\title{
Intercultural communication problems relating to translation from English into Sesotho
}

\author{
AS MOTSEI $^{1}$
}

\begin{abstract}
In this article, certain translative communication problems associated with the linguistic and stylistic differences between English and Sesotho are identified and discussed. With a view to help improve translation between the two languages where inaccurate and stilted communication frequently occurs, issues of equivalence, fidelity/faithfulness and the purpose of translation are delved into. It is furthermore argued that in South African multilingual contexts, like legal courts, criminal cases/hearings and hospitals clinics and similar health establishments, inaccurate translation and/or misinterpreting can lead to serious miscarriages of justice and poor service delivery. The reasons for such unfortunate eventualities sometimes relate to the translator-interpreter's poor understanding of the cultural factors behind the English or Sesotho message. As such, emphasis is lain on the need for a translator-interpreter's cultural understanding of the source language/text $(\mathrm{SL} / \mathrm{T})$ and target language/text $(\mathrm{TL} / \mathrm{T})$ to deliver an accurate version (in the target language or text $-\mathrm{TL} / \mathrm{T}$ ) of the original message. It is furthermore shown that one cause of social and legal injustice is closely related to the translatorinterpreter's insufficient knowledge of both the English and Sesotho culture as it exists in grammatical forms, idiomatic structures, collocation patterns and stylistic patterns of the $\mathrm{SL} / \mathrm{T}$ and the TL/T.
\end{abstract}

Keywords: translation processes; interpreting practice; equivalence; fidelity; translative purpose; cultural influences; intercultural communication; legal discourse; social justice.

\section{Background}

Prior to 1994, the bilingual policy and the legal system in the Republic of South Africa tended to privilege only the White speakers of English and Afrikaans, the official languages of civil life. A significant number of the South African populace was prevented from full participation in the social and political life of the South African system. The African populace could not access full legal services in the justice system neither derive significant 
benefit from the country's education, nor gain any health and welfare rewards from public institutions. The situation was partly due to barriers created by the system's overriding reliance on the two non-indigenous languages, English and Afrikaans (Deprez \& Du Plessis, 2000: passim). The inherently unjust and racially discriminatory language policy had, therefore, the effect of marginalizing the speakers of African indigenous languages like Sesotho.

Even though the nine indigenous African languages were granted official status in 1996, the advantages accruing from the dominant use of English and Afrikaans in official circles, continue to disadvantage non-native speakers in the new democratic state. The ideal of all South Africans enjoying equal treatment and obtaining equitable use of government social and legal services still has to reached. Various scholars (Tollefson, 1991; Skutnabb-Kangas, 2000; Alexander, 2002; Beukes, 2004) have argued that for African citizens, particularly, to acquire fairness and respectability for themselves in the public domain, their indigenous languages should be accorded the socio-political status similar to English and Afrikaans. In other words, the nine African languages ought to be employed just as regularly and widely as the other two.

At present, the value attached to using an African language like Sesotho in most social situations is quite low in comparison to resorting to English and Afrikaans. Thus, the actual or de facto circumstances require interventions such as interpreting and translation for African language speakers to gain the 'sociolinguistic power' (Fairclough, 1995) that will allow them to fully access the legal, health and educational facilities of their country.

\section{Relevance of social justice}

The notion of access to the social and political goods and services through one's home or native language, in a multilingual South Africa, needs to be defined and relocated within the de facto circumstances pointed out earlier. Social justice can be defined as, the responsibility of state institutions/organs to ensure equal treatment of the citizens and to uphold human rights and the dignity of each person in enjoying the freedoms and services guaranteed and enshrined in the country's laws. In the South African context, social justice is also about state organs taking direct action to redress historical inequities and inequalities. Those include the freedom to use the 'language one understands best to access opportunities in the health, education, legal and/or justice services' and the economic rights of the country (Tollefson, 1991: 8-12; Skutnabb-Kangas, 2000: passim). The latter statement implies that information and knowledge relevant to various spheres of South African life should be available and accessed through a medium that not only promotes but also guarantees equal opportunities' (Fairclough, ibid.). In pursuance of the principles of equal opportunity, the Bill of Rights and Section 6, of the Republic of South Africa's Constitution (Act No.108 of 1996) were crafted in order to bring that into legal effect. This implies that everyone has the legal and legitimate right to use the language they understand best and to participate in the cultural life of his or her choice. This is important especially regarding the ordinary person's obtaining access to the social, political official and legal services of the country.

In fact, nowhere are these rights crucial as in the legal courts where justice has to be seen to be done, as Section 35(3) and 35(4) of the country's democratic Constitution enjoins the citizens: 
Every accused person has a right to a fair trial which includes the right to:

(a) To be informed of the charge ... in sufficient detail,

(k) To be tried in a language that the accused person understands or, if that is not practicable, to have the proceedings interpreted in that language.

(and) Whenever this section requires information to be given to a person, that information must be given to that person in a language that the person understands.... (Justice College Handouts, 2004a: 39-41).

It is evident therefore that where, in a court case or trial, the services of a translator or an interpreter are needed, especially if it involves a non-native speaker of either or both English and Afrikaans, the person chosen or appointed as a communication intermediary should be well-versed in languages the court will use (Justice College Handouts, 2004a: ibid.). If there is any neglect in that regard, a good deal of social injustice will be done to the accused and those who are closely associated with him or her. This issue will be discussed further in later paragraphs.

\section{Argumnents advanced}

This article argues that although translation is sorely needed in the South African multilingual reality, the processes and procedures of translation per sè, should not be understood as being without pitfalls. Indeed, the conventional definitions such as of Bell (1991: 5), Catford (1965: 20) and others, overlook the problems and give the impression of translation processes as basically straightforward. Bell, for instance, comments in the following way:

$$
\begin{aligned}
& \text { 'It is]... the expression in another language (or target language) } \\
& \text { Of what has been expressed in another language (or the source language) [whilst] } \\
& \text { preserving semantic and stylistic equivalence.' }
\end{aligned}
$$

Catford presents essentially the same view where he states that:

$$
\begin{aligned}
& \text { 'translation is communication of the meaning of a source-language } \\
& \text { or text by means of an equivalent target-language text ... }
\end{aligned}
$$

These rather broad explanations of what goes into the processes of translation present a perfect world in which the translator is in full possession of all skills and knowledge required by this type of interactive communication. The definitions of Bell, Catford and others deal essentially with pristine, monolingual and bilingual conditions within socio-politically stable societies. On the other hand, these conventional definitions falter, for example, where multilingualism is the norm and where languages as dissimilar as English is from Sesotho are involved.

In contrast to traditional positions, modern experts have come to contend that translation is rather complex enterprise. Writing in their edited publication, Baker and Malmkjaer (1998) and several other contributors define the translation generally as linguistic work that is hardly the 'mere replacement of textual material in one language (source text/ST) by their equivalent in another language' (target text/TT). 
As such, one central argument made herein, is that the able translator, expert interpreter, as Snell-Hornby (1988) calls them, has to possess more than ability in the two languages involved. In their repertoire, the translator-interpreter must own skills and strategies to fathom meanings and implicatures of both the SL/T and the TL/T. In addition to that, according to Newmark (1988), he must be able to negotiate and broker the cultures and/or cultural nuances lying behind any text or utterance they are given.

\section{The Importance of culture in translation}

The definition of 'culture' as given in the Concise Oxford Dictionary varies from the description of the 'arts'. More specifically concerned with language and translation, Newmark (1988:94) defines culture as 'the way of life and its manifestations that are peculiar to a community that uses a particular language as its means of expression'. In this, Newmark recognizes and acknowledges that each language group has its own culturally specific characteristics that feature within their language. He further states that operationally he does 'not regard language as a component or feature of culture' (Newmark 1988:95). This is a directly opposite view to that taken by Vermeer who states that 'language is part of a culture' (1989: 222). According to Newmark, Vermeer's stance would imply the impossibility to translate whereas for the latter, translating the source language (SL) into a suitable form of TL is part of the translator's role in trans-cultural or intercultural communication. The researcher share the same view with Vermeer on culture because nothing defines culture as distinctly as its language, and the element of language that best encapsulates a society's values and 's beliefs.

\section{Theoretical framework}

Traditionally, translation between languages has been explained in terms of two basic principles used to determine the effectiveness of the process and outcome. 'Fidelity' and 'equivalence' were the defining hallmarks of good translation, from the days of St Jerome, through the mid-18 ${ }^{\text {th }}$ century missionaries, up to the early 1900s (Nida, 1980: passim). However, translation has come to be re-defined, by later theorists and practitioners like Nida (ibid.), Snell-Hornby (1988) and Baker (1992), as the transfer of meaning from one language into another. It has therefore become convention to argue that the translative process is not the transfer of words from one language into another. Put in another way, the translator is expected to translate the meaning of what is being said, rather than doing it word-for-word or metaphrastically (Baker and Malmkjaer, 1998). According to Newmark (1980: passim) and Baker (1992: 6-17), the principle of equivalence even though relevant, cannot be really attained in translation processes. These writers go on to characterize the principle as a 'failure' since no two languages are fully or exactly interchangeable.

This is because every language comprehends and describes the world and reality in its own and different way. Translation does not necessarily imply the transference of syntactic patterns only but the meaning of a message conveyed in a communicative act. Different languages also have different grammar, different word orders, sometimes even words for which other languages do not have any equivalents. The English spoken by a scientist may have words which a simple farmer cannot even start to imagine. And the farmer is likely to have words for things the technologist never dreamed of. It is often extremely difficult to express semantic and stylistic equivalence from the source text (ST) to the target text (TT). 
There are factors which need to be taken into account during the process of translation. A translator may be called to translate a text, without taking the client into consideration. The initiator aims at receiving a translated final product that is without unnecessary errors. That is the essence of any assigned translation task. This article therefore demonstrates translation problems as encountered by the translator of the source text into the target text in Sesotho.

\section{Problems of translation identified in Sesotho target texts}

The article presents the functionalist theory of translation as expounded by translationists like Nord (1992: 14.). Her argument is that principles such as fidelity concerns intertextual coherence translatum and the source text, and stipulates that some relationship must remain between the two. Like other writers on translation processes fidelity or loyalty and equivalence are a means to an end like an authentic translation product (Baker and Malmjakaer, 1998: passim). As will be shown, the functionalist principles will assist in the identification and analysis of the intercultural problems associated with translating from English into Sesotho be classified according to two fundamental principles of the practice of translation.

The first principle, namely fidelity or loyalty, underlies what is termed the linguistic theory of translation. The 'fidelity' that the TT/L owes to the ST/L is fundamental to and plays a dominant role in translation processes to produce authenticity in the quality of a translated text. In other words, the linguistic style of the ST can often override the style of the recipient language (TL or TT) on account of the emphasis on fidelity. Baker (1992) refers to this relationship as that non-equivalence between the ST and TT at the word, the sentence as well as, the text levels. The second principle of the loyalty or fidelity to the ST, refers to the interplay of culture as the background or context within which the translation should be made. This principle focuses largely on the extra-textual references, particularly with regard to the formulation of the TT or in that the formulated 'translatum' remains true to the original meaning in the ST. According to the functionalist theoretical framework propagated by, among others; Nord's emphasis is that, a translation that serves both the linguistic but mostly the cultural interests of its speakers will be perceived as functional within the limits of this article. It is then against this understanding as the environment that I would demonstrate that translation is not only a linguistic but also a cultural transference. I hope to argue at the end that most of the problems are essentially caused by undermining the sociocultural factors around the target readers. In other words, even if identified problems can be largely linguistic or semantic, the underlying factors are seen as the dynamics of the culture that characterizes both the source text and the target language or text. With reference to the two fundamental principles cited above, the idea in this case is to demonstrate how translation problems occur in Sesotho language and how culture manifests itself as the underlying factor behind such problems.

To a question like, 'Can social justice be derived through translation?,' the answer can be derived from what translation theorist's like Lotman (1978: 211-32) and Bassnett (1980:23) have argued. According to Nida (1964), Lotman's theory states that 'no language can exist unless it is steeped in the context of culture; and no culture can exist which does not have at its centre, the structure of natural language' is pertinent to social justice issues. This also goes to what Bassnett points out in the following way: 'the translator must tackle the SL text in 
such a way that the TL version will correspond to the SL version' The latter definition suggests that the correspondence needs to come about in terms of both the linguistic and cultural aspects of the ST and the TT. If there is a lack of such equivalence, the final TT will sound ineffective and the message will have been distorted.

\section{Problems of non-equivalence}

According to Baker (1992:17), the choice of a suitable equivalent in a given context depends on a variety of factors. Some of these factors may be strictly linguistic while others may be extralinguistic. However, the choice of a suitable equivalent will always depend on the translator.

\section{Equivalence at word level}

Baker (1992: 20) explains that non-equivalent at word level means that the target language has no direct equivalent for a word occurs in the source text. She points out that different kinds of non-equivalence require different strategies; some are straightforward while others are difficult to handle. The following are common types of non-equivalence at word level with examples from English to Sesotho:

\section{Culture-specific concepts:}

The source language may express a concept which is totally unknown in the target language culture. For example:

- Banquet which means a large meal or feast, complete with main courses and desserts. It usually serves a purpose, such as a charitable gathering, a ceremony, ...en.wikipedia.org/wiki/Banquet

- Matric dance is (South Africa) a formal ball for scholars in their final year of school. It is also thought to be a metaphoric pre-wedding day of a learner, which is why lots of attention and effort is put into it. It is a celebration of the end of your school career (graduating into the adult life I should say) Read more: http://wiki.answers.com/Q/What_is_a_matric_dance\#ixzz16rEWTEmk

- Gala dinner - A private room reserved for a group to pre-order off a set menu and seated in banquet or cabaret. wiki.answers.com/Q/What_is_a_Gala_Dinner

- Ball dance - A ball is a formal dance. The word 'ball' is derived from the Latin word "ballare", meaning 'to dance'; the term also derived into "bailar", which is the Spanish and Portuguese word for dance (verb). In Catalan it is the same word, 'ball', for the dance event.

The above concepts, they may relate to a social custom or even food of a source text but to the target language in which in this case is Sesotho, they may be translated as 'mokete' (feast) irrespective of the type of the feast. These concepts are culturally specific and are part of those English concepts rarely understood through a Sesotho cultural perspective or by being literally translated into Sesotho. The problem of non-equivalence at the lexical level therefore has to be understood as fraught with many pitfalls since there is often little equivalence, at the word level, between the source language and the target language. There are many more problems are inherent in non-equivalence at word level, as many translation theorists and interpreting practitioners have argued. 


\section{Translation of SL/T semantic complexity}

In translating into a second language, the understanding of source text is the easier aspect, the real difficulty is in producing a target language in which the composition does not come naturally. In the following circumstances, single words in a sentence sometimes can express a more complex set of meanings than a whole sentence. Study the following sentences where italised single words can express a complex meaning.

(i) SL/T: (1): The car is out of control. (Idiomatic English).

-Complexity in syntax: Subject Deletion and Object Fronting:

'The car' is the dummy subject/Not syntactically real subject.

$T L / T^{*}(1 a): \quad$ Koloi e tswile taolong.

-Passive Voice structure is repeated holus-bolus in the Sesotho version.

TL/T(1b): Mokganni o hlotswe (ke) ho laola koloi.

-Active Voice construction. Subject is: 'mokganni'. Copular deletion: 'ke'.

TL/T *(1c): $\quad$ Mokganni o ile a bloleha ho kganna hantle.

(Justice College Notes, 2004b.)

Semantic complexity is reflected in both (1a) and (1b), because of the 'fidelity-principle'; even though (1b) has somewhat greater syntactic fidelity because of Object-Deletion: 'koloi' is implied in the deep structure of both the English and the Sesotho sentences.

During court cases, Object Deletion like the one discussed above, can cause problems for a Witness because the law and legal discourse demands specifics and directness when evidence is given and has to be later weighed (Gibbons, 2004) A witness who states the following (*1c): 'Mokganni o ile a bloleha ho kganna hantle!', could be interrogated by the Magistrate and/or the Defence as to what they are actually referring to and whether the driver/'mokganni' could not drive because they were unable to drive or were in some way disabled or physically challenged, rather than being drunk, as in utterances like $(4 a)-(4 c)$ cited in the paragraphs below. Since argument and verbal contestation are part and parcel of court proceedings as well as being at the heart of most legal discourse, as writers like to point out, any Witness who cannot fully clarify and/or specify what they mean, stands to loose their case. Thus, translation and interpreting in court, as anywhere else, has to be accurate and meaningful lest injustice is caused. Thus, the Sesotho idiom is undermined.

(ii) SL/T: Many people lost their lives in a car accident.

TL/T(2b): Batho ba bangata ba lablehetswe ke maphelo a bona

kotsing ya koloi. (Literal/Metaphrastic translation).

TL/T (2c): $\quad$ Batho ba bangata ba blokahalletse kotsing ya koloi.

(Semantic/Paraphrastic translation) 
In the first translated option, the translator emulates and/or produces a lexical equivalent of the source language/text and thereby ignores fidelity rule. While doing so, the translator forgets that:

- He/she communicates with different readers who have a totally different world view. In (1) the car can be said to lose control within the source text linguistic structures, but that will be questionable and controversial among the Sesotho target readership. On the other hand, in (2) the word 'lost' is said to lose its meaning due to the complexity of the meaning explain in TT (1) and the translation is said to be questionable and controversial to the target group.

- The collocational pattern assumed in the above statement is critical in the sense that the car cannot be expected to be out of control on its own.

- Moreover, the translation does not feature efficiently within the limits of the African culture in general, and the Sesotho translation in particular.

- As a result of this oversight on the part of the translator, the entire translatum cannot the classified as functional on the part of its intended readers.

In the second translation option specified above TT (2) it becomes obvious that the translator takes the intended readers on board in the translated outcome of the given source text. The translator appears to have a thorough perspective of the dynamics of the Sesotho language as well as the attendant culture of an acceptable utterance, as Possa and Makgopa (2010: 2-3). The following are the salient points worthy of mention in the analysis of the second translation option:

- The translator appears to know that it would be prudent to bring in the driver of the car to make sense of the assertion made as the given source text (because the car cannot simply lose control on its own).

- Only the translation that communicates sense on the part of the intended readers can be said to be functional to the targeted group. The second translation option thereof characterises itself as functional in its relationship with the source text as well as its presentation of the cultural interplay directed at the intended Sesotho target readership.

\section{Some idiomatic meaning distinctions in English and Sesotho lexis}

There often are wide semantic differences between an SL and a TL word or expression which may be a potential pitfall for the interpreter-translator who focuses only on lexical equivalence to do their translative work. A relevant example is the neutrality of the English words relating to death like die, dead, and corpse when contrasted to the their equivalent but culturally loaded ones in Sesotho: shwa, shwele and setopo. The cultural nuances between Sesotho and English lie in the fact that in the three terms, English applies the notion of 'death' to all things, whether they be human, non-human and/or inanimate. Sesotho, on the other hand, employs the same three words selectively, by making a distinction between human and non-human things.

Thus, the following sentences illustrate the cultural meanings that are not readily visible or obvious to an unsophisticated and an untrained interpreter-translator: 
$S L / T(3 a) \quad$ 'The grass is dead from the drought/The grass has

been killed by drought' could be appropriately translated as (3b):

TL/T (3b) 'Jwang bo shrwele ke komello/Bo bolailwe ke komello.'

A further example of the cultural dimension in Sesotho is that only setopo would be used in reference to human entities and hardly ever to non-human things. In this sense, the English word carcass would be a relevant substitute for a Sesotho expression like setopo sa ntja, which accounts for the non-human and animate entity:

$T L / T^{*}(3 c)$ : Setopo sa ntja ya mapolesa se fumanwe; yona

e ile ya shwa ha e betswa ka majwe ke bashemane.

SL/T (3d): The carcass of the police dog has been found; (it died when) the boys (had) stoned it (to death).

The important point with regard to sentences *(3c) and (3d), is that the Sesotho expression is somewhat stilted and bookish since it arises out of the lexical and cultural tyranny of the $\mathrm{SL} / \mathrm{T}$, rather than the ethnolinguistic nuances of the TL. A much more meaningful and appropriate rendering would have been the following:

\section{$T L / T(3 e):$ Ntja ya maponesa e fumanwe (e shwele); e ne e tlepentswe \\ ka majwe (ke bashemane).}

Also significant is that a residing dimension in Sesotho y have same meaning as a word in SL but may have a different expressive meaning. For instance the word "die" in English may take a different expressive meaning in Sesotho depending on who or what has died. An enemy or an animal 'dies' but a respected and loved person 'passes away/has passed away.' The cultural nuances and subtleties in the following Sesotho sentences become clearer in the back-translation English equivalents below:

SL/T (4a): $\quad$ Motho ya blokahetseng e le Leselamose kapa

Momoseleme o patwa pele tsatsi le dikela.

TL/T (4b): $\quad$ A person belonging to the Muslim faith has to be

buried before sunset.' (Equation/Equivalence/Matching)

SL/T (4c): $\quad$ Ntate o blokahalletse mosebetsing; moepong wa Marikana.

TL/T (4d): My father passed away at his workplace; in the mines of Marikana." ( Amplification)

SL/T(4e): $\quad E$ mong wa masole a thuntsweng a be a blokaballa ntweng tsa kwana Bangui, naheng ya CAR,

ke mangrwane Thakane.

$T L / T(4 f): \quad$ 'One of the soldiers that were shot and died in the fighting at Bangui, in the country called CAR, was my aunt Thakane.' (Reduction E' Repackaging)

Consideration of the cultural implications of an SL/T text about to be translated implies recognizing all of the problems associated with non-obvious meanings that require highlighting and capturing in the TL/T. In tricky cases such as those in six underlined 
sentences above, the best or most appropriate translative strategy is dictated by the cultural nuances of the original or the SL/T. The various strategies of matching, reduction, amplification and repackaging of meaning can be seen in the TL/T examples given as (4a) (4f) above.

\section{Translation of idioms and proverbs in legal contexts}

\begin{tabular}{|c|c|}
\hline$S L / T(5 a):$ & $\begin{array}{l}\text { A leopard cannot change its spot. (means: 'things cannot change their } \\
\text { inner nature'). }\end{array}$ \\
\hline$T T^{*}(5 b):$ & Motho ha a fetohe letlalong la hae. (Metaphrastic translation) \\
\hline$T T(5 c):$ & $\begin{array}{l}\text { Motho ha a fetohe semelong sa hae/Nkwe e shwa le mebala. } \\
\text { (Paraphrastic translation) }\end{array}$ \\
\hline
\end{tabular}

The first translation option (5b) signifies a failure to recognize the idiomatic meaning of the $\mathrm{SL} / \mathrm{T}$ expression which is almost untranslatable, in the sense that the true meaning of the English idiom cannot be transferred holus-bolus into Sesotho. If the interpreter-translator does so, the outcome is a culturally strange meaning or a metaphrastic version that would alienate Sesotho native speakers who are unfamiliar with English idiom. Several important points have to be made in regard to what are the unseen pitfalls of metaphrastic translation:

- The gist of the message communicated in the SL/T is lost seeing that the translator does not recognize the fact that the language used is figurative.

- The lack of an equivalent figurative expression in Sesotho, the translator goes for a word-for-word rendition which, according to Baker (1992) cannot be maintained at all grammatical and pragmatic levels.

- The translation depicts itself as non-functional at cultural level seeing that it does not capture the basic purpose intended for the target readership, by the writer/translator.

The second version (5c) is reckoned to be a functional translation at the cultural level because it correctly recreates both the linguistic and semantic features of the original. Of great importance, the particular translation option implies that the translator operates according to what was actually contained in the original SL/T or in line with the purpose of translation. A translation that satisfies the needs of the intended group in terms of a given purpose and the implied socio-cultural background tends to be functional and efficient in communicating the desired and therefore the important information to the target group.

The functionality of the target text assigned by the socio-cultural elements of the translated text or product is quite important in the following examples:

$S L / T(6)$ : He drove the car under the influence of liquor. ((English idiom)).

TL/T (6a): $\quad$ O ile a kganna koloi tlasa tshusumetso ya tabi. (Metaphrastic; this is wordy Sesotho and is 'legalese' in form.).

TL/T (6b): O kgannile koloi a tahilwe. (Precise translation; might be less

appropriate in legal courts where exactness in required.).

TL/T(6c): O kganna koloi a itjelletse. (Paraphrastic; more idiomatic

Sesotho with both deferential plus comical overtones).

TD, 9(3), Spec. ed., December 2013, pp. 608-623. 
Analysis of the translation options given above reveals the following issues:

- The first translation option (6a), might not be conversationally functional since it distorts the message intended in the SL/T (6), which is 'influence', rather than 'tshusumetso' or driven/impelled/encouraged by liquor. For its meaning, it relies rather heavily on the literal meaning of the individual lexical items of the ST. In another sense, the Sesotho rendition (6a) proves the alleged crime of drunken driving before the facts have been considered. The translation or interpreted version could arguably be detrimental to the accused person, and prevent his right to be 'presumed innocent before being proven guilty' (Justice College Notes, Criminal Procedure, 2003.).

- The second version (6b) is functional because it captures communicatively the meaning essence or message intended by the SL/T However, (6b) might be less functional in legal contexts since it merely states facts about the physiological condition of the driver. A prosecutor who is after finding someone guilty appropriate or quite. Although (6a) sounds like typical court language, in general it comes across as communicatively wordy and formal, in the legal sense. Where verbal potency is required in order to decide matters of retribution, punishment, life and death, (6a) stands as a relevant utterance. Indeed, where clear evidence and accurate statements are required such by a legal court, the interpreter rendering a TL utterance like (6a) from the SL (6) input, will be highly commended. Yet the consequences for the accused driver could be severe if he/she were innocent.

The third option (6c) is more appropriately used where reference is being made to someone older or of higher social standing than the speaker. Hence, option (6c) is culturally more acceptable in less formal contexts than in a court because it also carries overtones of familiar and mocking respect. In cultural communicative settings and within world-views or social philosophies of African people, particularly the Basotho, the older generation is always 'to be respected and venerated'. In interacting verbally with Basotho seniors, the younger person who works as an interpreter, a nurse or even a doctor is expected to treat and listen in a fair or just way,' as Moleleki (1993: 36) and Mokitimi (1991: passim) point out.

\section{Differences in interpersonal, relational and kinship terms}

The latter discussion about Basotho people's cultural precepts and expectations is closely connected with communication between members of a family, clan or larger community group. In this sense therefore, kinship terms become an area relevant for showing how translation deals with it.

- In some languages the relational or interpersonal perspective is more pronounced than in others. For example, in English the word 'brother' denotes any male sibling, whereas in Sesotho a more distinctive denotation is made about the position of the sibling relative to the speaker. The equivalent Sesotho term for 'brother' is 'moholwane', which refers to an older male sibling while 'monyane', is one's younger brother. The distinction that is made, if at all, sometimes depends for meaning on the gender of the speaker. 
- Where the TL does not have particular gender distinctive forms but uses a general word, often there occurs confusing translation. A relevant example is in English where pronouns like 'he/she' and 'it' denote a person's or something's gender. In Sesotho no such lexical distinctions are made, and instead ' $O$ ' is used in all instances. As such, an English utterance (ST) using several distinctive pronouns like she, her and their, in Sesotho is rendered without making those gender differences clear, as the two examples seek to highlight:

$S L / T$ (7): 'The bus was hijacked while the driver had alighted.

She had gone off to fetch, from their office, her ticket

batch and change' [for the passengers].

TL/T (7a): Bese e ile ya utsuwa ka nako eo mokganni a theohileng. O (ne a le siyo kahare, a ile ho) a tlohile ho ya lata sehlotshwana sa ditekete le tjhelete ka ofising ya bona.'

As can be seen in the Sesotho text (TT), the second gender identification form or the pronoun 'her', is missing. Indeed, none of the feminine denotations are directly spelled out and only 'their' is correctly translated as the plural pronoun 'bona' in the equivalent Sesotho version. The implications of such language differences have been shown, by Moeketsi (1999: passim), Hlophe (2004) and others, to have serious implications when interpreting court in cases involve victims and accused perpetrators of different genders.

Where the TL distinguishes greater or lesser meaning than SL, e.g. cousin, 'motswala' which in Sesotho refers to my uncle or aunt male and female children. 'Uncle' in English refers to both my father' and mother's brother whereas in Sesotho it usually refers to one's mother's brother while the English 'aunt' refers to both one's fathers and mother's sister. In Sesotho 'mangwane' refers to someone's mother's younger sister. What these kinship terms imply is, therefore, that 'mangwane', 'motswala', 'malome' define blood relations on a wider scale encompassing the family hierarchy tree, rather than narrowly in terms of oneself, myself and one's closest and immediate biological parents.

\section{Medical/Health terminology}

Medical terminology presents the kind of challenges that typify the cultural or ethnolinguistic nuances every translator and/or interpreter must grapple with to render effective or meaningful target text(s). Scientific fields such as medicine, health and anatomy typically employ registers overlain with peculiarities and particulars of knowledge. While the latter often are not highlighted or marked in ordinary English as well as in Sesotho speech, such levels of understanding and meaning are quite important in the courtroom, the clinic and hospital.

Consideration of the list given below, with English terms in the first column vis-à-vis the Sesotho ones in the second column, reveals the latter to be direct lexical equivalents of the former. In contrast, the third column while focusing on anatomical accuracy, is cognizant of the 'cultural dynamism' and the restrictions (Possa and Makgopa, 2010) surrounding the contextual uses of the longish terms and phrases. 
Thus, even in a public institution like a hospital or a courtroom, the efficient translatorinterpreter would be wary and conscious of the need to avoid using the second column terms. In a sense, the well-trained and skilled communication intermediary between a Witness and an Accused, the Victim and the Prosecutor/Magistrate, the Counselor and the one receiving therapy/counsel, as well as the messenger of the doctor to the patient is obliged to possess what Tollefson and others (1991: ii-iv and passim) have called 'critical language awareness' or sensitivity to the socio-cultural side of a language.

Awareness of their vulgarity and/or profanity would signify would mean that: (1) the translator-interpreter knows the medical and anatomical nuances of the English source terms; (2) that the accuracy of the Sesotho terms is essentially medical, but that (3) those terms are not socially acceptable; and finally, (4) that he/she has to resort to the more suitable and appropriate term(s) from column three. The latter column consists of terms that are more socially acceptable or respectable 'blonipha/tlhompho' terms (Mokitimi, 1998; 45-52) than the taboo ones in the first translated column.

\begin{tabular}{|l|l|l|}
\hline Medical term & Translated Sesotho term & Hlonipha' term \\
\hline Vagina & nywana & Botshehadi ba mosadi/senana \\
\hline Penis & kwae & botona ba monna/molamu \\
\hline Buttocks & se-/dibono & leraho/maraho \\
\hline Sex/intercourse & kotano/ho kotana & ketso tsa thobalano \\
\hline Testis & le-/marete & ditapole \\
\hline Anus & mosono & motete \\
\hline To loose libido & Ho se tsohelwe & $\begin{array}{l}\text { Malamu ha o pole/moshemane ha a } \\
\text { sebetse/thipa ha e sehe }\end{array}$ \\
\hline
\end{tabular}

In a hospital or clinic where an illiterate, elderly African woman is consulting an Englishspeaking gynaecologist, the services of a culturally-conscious interpreter might be needed. Such an interpreter, whether they be male or female, would instantly know that they have to avoid any of the medical/anatomical terms in the first column (Justice College Handouts, 2005). The Ubuntu-Botho precepts of decorum or the implicit respect of the elderly within Sesotho culture and the broader African context, will dictate that 'blonipha' terms be used throughout. Unless this is done, the dignity of the older woman will be undermined and she would be consequently offended and refrain from taking the gynaecologist's therapeutic and/or medical advice. Inadvertently, the old woman would lose faith and trust in public health-care facilities, as Maseko and Nosilela (2010: 21-22) warn, largely because her linguistic human rights were violated by communication that affronts her dignity. Thus, when translating, it is important to consider not only the lexical impact on the TL listener or reader, but also that one has to be attentive to the manner in which cultural nuances of speech influence the outcome of the translation or interpreting target. In other words, the translator-interpreter ought to always cultivate an awareness of those linguistic and cultural facets that might be negatively perceived, in the way the lexical items cited in column two would.

\section{Conclusion}

Observations deriving from the discussion in the article are, among others, the following:

- That translation is not a mere linguistic transference of lexical items from one language to another (i.e. from the SL/T into the TL/T) or metaphrastically; 
- That the target text cannot be functional (according to the fidelity-loyalty principle), if the translation processes are not rooted in thorough understanding and knowledge of the socio-cultural or ethnolinguistic implications of both the source language and the recipient language of the target group(s).

It is clear that translation that focuses exclusively on the translator's language ability rather than on the cultural nuances of both the SL/T and the TL/T, can lead to the kind of effective communication required in the public and social spaces of South Africa. However, a translation practice that ignores the legacy of past linguistic injustice as discussed earlier, will be fraught with intercultural misunderstanding, communication difficulty and lack of cooperation with governance perceived as delivering bad service.

The attainment of social justice for Sesotho speakers in public institutions like legal courts and in health facilities, can probably be achieved when and where meaningful communication through accessible translation services and products occur. In the new dispensation of welltrained translator-interpreters, the capacity to manipulate source texts in terms of the sociocultural and functional demands would attain for Sesotho speakers the linguistic rights to dignity and a self-expressive identity. Finally, it is recommended that research institutions initiate cross-cultural studies in translation and/or begin developing translation courses that inculcate skills around communicating the socio-cultural nuances of texts produced in multilingual circumstances, as Possa and Makgopa (2010) also suggest.

\section{References}

Alexander, N. (2002). An Ordinary Country: Issues in the Transition from Apartheid to Democracy in South Africa. Pietermaritzburg: University of Natal Press.

Baker, M. (1992). In Other Words: A Coursebook on Translation. London: Routledge, Taylor \& Francis Group.

Baker, M. \& Malmkjaer, K. (eds). (1998). Routledge Encyclopaedia of Translation Studies. London: Routledge.

Bassnett, S. (1980). Translation Studies. London: Methuen.

Beukes, A.M. (2004). The First Ten Years of Democracy: Language Policy in South Africa. Paper read at the $10^{\text {th }}$ Linguapax Congress on Linguistic Diversity, Sustainability \& Peace, 20-23 May,2004. Barcelona, Spain. [Available: http://www.linguapax.org/congress04/pdf/1_beukes.pdf

Catford, J.C. (1974). A Linguistic Theory of Translation. London: OUPress.

Campbell, S. (1998). Translation into the Second Language: Applied linguistic and language study. Edinburgh Gate: Longman/Addison Wesley.

Constitution of the Republic of South Africa, The. 1996 (Act No. 108 of 1996). Government Printer: Pretoria.

Deprez, K. \& Du Plessis, T. (eds.). (2000). Multilingualism and Government. $1^{\text {st }}$ Edition. Pretoria: Van Schaik Publishers. 
Fairclough, N. (1995). Language and Power. London: Longman.

Gibbons, J. (2004). Language and the Law. In: Davies, A. \& Elder, C. (eds.) The Handbook of Applied Linguistics. Malden, MA: USA: Blackwell Publishing. pp 285- 304

Hlophe, J.M. (2004). Receiving justice in your own language - The need for effective court interpreting in our multilingual society. Paper Delivered at the University of Cape Town, 17 September 2003. Advocate Forum, April, pp 42-47.

Justice College Handouts. (2003). Basic Principles of Court Interpreting: Criminal Courts. No. 106. Edited by: Mr BJ King 2003; Written and Updated by: Adv. E. Mathe and Chief Inspector, Mr A.A. Mahlangu, 2000-2002. Department of Justice and Constitutional Development (DoJCD); Proes Str., Pretoria.

Justice College Handouts. (2004a). Specific Charges for Court Interpreters in Setswana and Sesotho. [The Criminal Procedure Act and Interpreting]. Compiled by: Chief Inspector, Mr A.A. Mahlangu and others, 2003-2004. DoJCD, Sunnyside, Unisa Campus Pretoria.

Justice College Notes. (2004b). Kimberley Courts \& the Northern Cape: Tutor of Court Interpreters' Visits - Makhudu, PDK. $7^{\text {th }}$ to $9^{\text {th }}$ June, 2004. DoJCD, Sunnyside, Unisa Campus: Pretoria.

Justice College Notes. (2005). Bail terminology, rights of the Accused at Beginning of the Trial: IsiXhosa, Sesotho, Setswana Interpreting Versions. Prepared and Updated by: Court Interpreting Tutors and retired Senior Inspectors: Mr S. Xhamela, Mr J. Matshisi, with Mr J. Mazibuko, Mr PS Baloyi, Mr PDK Makhudu, 2003-2005. DoJCD, Sunnyside, Unisa Campus, Pretoria.

Lotman, J., Uspensky, B., (1978). On the Semiotic Machanism of Culture', New Literary History, Vol 2, The Johns University Press

Maseko, P. \& Nosilela, B. (2010). "They use MY medicine together with THEIR muthi": A Motivation for Integrating Cultural Awareness and sensitivity in the IsiXhosa Pharmacy Programme at Rhodes University. In: Southern African Journal for Folklore Studies. May, Vol. 20, No. 1., pp 21-36. [Available:
[A http://www.safos.org.za ].

Moeketsi, R.M.H. (1999). Discourse in a multilingual and multicultural courtroom: A court interpreter's guide. $1^{\text {st }}$ Edition. Pretoria: JL van Schaik.

Mokitimi, M.I. (1991). A Literary analysis of Sesotho Proverbs (Maele). Unpublished doctoral thesis. University of South Africa: Pretoria.

Moleleki, M. M. (1993). Makokonana a Neanotaba le Dingolwa tsa Sesotho. $1^{\text {st }}$ Edition. Randburg, South Africa: Vivilia Publishers \& Booksellers.

National Language Services. (2003). South African Language Bill.-Revised 04 April 2003. Department of Arts and Culture: Pretoria.

Newmark, P. (1980) The translation of Metaphor. Babel 26:2, p93.

Newmark, P. (1988) Approaches to Translation. Oxford: Pergamon Press. 
Nida, E A. (1964). Principles of Correspondence. The Translation Studies Reader, London: Routhledge.

Nida, E A. (1991). Theories of Translation. Leiden, The Netherlands: E.J. Brill.

Nord, C. (1992). Cultural Implication for translation. Manchester, UK: St Jerome Publishing.

Nord, C. (1997). Translation as a Purposeful Activity. Manchester, UK: St Jerome Publishing.

Possa, R.M. \& Makgopa, M. (2010). The Dynamism of Culture: The Case of Sesotho Proverbs. In: Southern African Journal for Folklore Studies, October, Vol. 20, No. 2., pp 1-12. [Available: http://www.safos.org.za ].

Skutnabb-Kangas, T. (2000). Linguistic Genocide in Education, or Worldwide Diversity and Human Rights? London: Lawrence Erlbaum Assoc.

Snell-Hornby, M. (1988). Translation Studies: An Integrated Approach. AmsterdamPhiladelphia: John Benjamins.

Tollefson, J. (1991). Planning Language, Planning Inequality. London: Longman.

Vermeer, H. (1988). Skopos and Commission in Translation Activity. The Translation Studies Reader, London: Routledge. www.afairerworld.org/_Justice_and_equity/ 